\title{
O TREINAMENTO DE PRÁTICAS CORPORAIS DA DANÇA: DE MURO A GUERREIRO, O TRABALHO COM A IMAGINAÇÃO NA COMPOSIÇÃO INSTANTÂNEA DE JULYEN HAMILTON
}

\author{
Maíra Simões Claudino dos Santos \\ Doutoranda em Dança na Universidade Técnica de Lisboa \\ mairadomar@gmail.com
}

Melanie Bales e Rebecca Nettl-Fiol, pesquisadoras da Universidade de Illinois Urbana-Champaign (Departamento de Dança), partem da premissa de que, na dança, o treino de práticas corporais não estaria apenas no lugar da construção de habilidades, mas sim no de invenção, descoberta e desenvolvimento da dança. $O$ treino de práticas seria assim um lugar generativo de arte e produção de conhecimento. A partir da composição instantânea, segundo a concepção do coreógrafo britânico Julyen Hamilton, este artigo propõe-se a discutir como o conceito de imaginação emerge e é trabalhado nas práticas corporais da dança. Para tanto, realizou-se uma etnografia de prática artística em que o campo privilegiado foi o próprio estúdio e workshops realizados em circuitos berlinense de treinamento da dança contemporânea entre janeiro e junho de 2015. As considerações metodológicas foram feitas com base em uma pesquisa da autora e de seu aprendizado de práticas corporais da dança como locus de um devir-coreográfico, via um processo de imersão na prática propriamente dita.

Palavras-chave

Hamilton. Treinamento. Imaginação. Composição Instantânea. Dança Contemporânea.
Melanie Bales and Rebecca Nettl-Fio, researchers from the University of Illinois Urbana-Champaign (Dance Department), have established the premise that, in dance, the training of body practices not only would be a place for building skills, but also one of invention, discovery and development of dance. The training of such practices would be therefore a generative place for art and knowledge production. This article aims to discuss how the concept of imagination emerges in the training of dance practices from the instant composition, according to the conception of the British choreographer Julyen Hamilton. For that purpose, an artistic practice of ethnography has been held in which the privileged field was the studio itself during training sessions held in Berlin's circuits of contemporary dance between January and June 2015. The methodological considerations are based on a research made by the author about her own body dance practices, conceived as a locus of a becoming-choreographic, a path into a process of immersion in the practice itself.

Keywords

Hamilton. Training. Imagination. Instant Composition. Contemporary Dance. 


\section{Introdução}

Este artigo é fruto de uma pesquisa maior, ${ }^{1}$ que envolveu uma imersão em treinos diários de dança na cidade de Berlim, chamada "treinamento para profissionais" (profitraining). Tratam-se de aulas e workshops que não são fixos, mudam a cada semana, e cuja ênfase recai sobre a dança contemporânea, a criação e até mesmo o balé clássico. Uma das questões com que nos deparamos logo de início foi a de como compreender a questão do treinamento nesses contextos, afinal em alguns espaços o que parecia prevalecer era a ideia de treinamento ligada a uma noção "do corpo hiper-treinado, do corpo anoréxico, do corpo-imagem ou corpo-robot, sem vísceras nem desejo, sem excesso nem sombra". (Lepecki, 2003, p. 7) Passamos então a identificar e a nos concentrar mais nos circuitos de treinamento/aula/workshops que realizassem um trabalho com dança contemporânea, sobretudo coreográfico e de criação, levando em conta seu caráter teórico e prático, dedicado também à sensação e à reeducação do movimento ou à Educação Somática.

O segundo passo consistia em descobrir como apresentar esses treinamentos para poder falar do corpo e da dança, visto que a palavra - treinamento - poderia remeter ao sentido acima citado, relativo por sua vez ao conceito de adestramento ou de "disciplina" de Foucault (1987), que se define por técnicas de controle a fim de tornar o corpo dócil e útil. Pudemos perceber então que o lugar do treinamento nesses contextos era permeado por práticas corporais da dança e muitas vezes imbricado em práticas do campo somático e em

1 Essa pesquisa é parte do doutorado que está sendo realizado pela autora. disciplinas orientais do corpo.

Como exemplo, para refletir sobre esse tipo de treinamento, gostaríamos de discutir o trabalho pedagógico do coreógrafo britânico contemporâneo Julyen Hamilton. Tal trabalho envolve um abordagem ligada à arte e concebe a técnica de exercício corporal de uma forma não estereotipada ou normativa. Seu pensamento coreográfico se desenvolve em torno das noções de "composição instantânea" e de performance. Ou seja, é um pensamento concentrado na cena, pois suas práticas corporais encontram-se desde 0 início relacionadas a elementos composicionais. A isso fundem-se práticas sobre espaço, tempo, escuta, presença, imaginação etc.

Para o escopo deste artigo elegemos a prática com a imaginação, a fim de compreendê-la, tal como ela emerge e é trabalhada. Ademais gostaríamos de refletir sobre a função do treino das práticas corporais da dança contemporânea que não estariam apenas no lugar da construção de habilidades (skill builders), mas sim no da invenção, da descoberta, da intensificação e do desenvolvimento da dança. As práticas, seriam assim, lugares generativos de arte e produção de conhecimento. (Bales e Nettl-Fiol, 2008, p. VIII) Para tanto, partimos de uma etnografia da prática artística, envolvendo o estudo do coreógrafo Julyen Hamilton, e ainda o fazer encarnado relacionado a investigações e experimentos artísticos ${ }^{2}$.

\section{Abordagem metodológica}

A presente etnografia resultou da imersão da pesquisadora no trabalho de campo e foi

$2 \mathrm{~A}$ parte relacionada com as investigações e experimentos artísticos não serão tratadas neste artigo. 
feita pela observação e participação nos treinamentos de Hamilton, pela construção de um detalhado caderno de campo e pela análise de documentos, tais como a descrição de todas as atividades pedagógicas desenvolvidas e os materiais de aula.

Para Marilyn Strathern (2014), o momento etnográfico é um momento de imersão que afigura ao mesmo tempo total e parcial, pois não é a única atividade em que o pesquisador está envolvido. Dessa forma, a pesquisadora considera que o tempo, mais que o espaço geográfico, tornou-se um eixo de separação. Quanto ao espaço em que atua o pesquisador etnógrafo, seja sua escrivaninha, seja o próprio campo, cada um oferece uma perspectiva sobre os demais. Ligado a isso, outro ponto a ser destacado é a questão da escrita como um segundo campo, sobre a qual a autora sugere inverter a ordem da pesquisa: ela enfatiza a necessidade de se analisar o momento da observação e de, inversamente, observar o momento da análise. Propõe-se assim uma ordem in media res, já que "o investigador não conhece de saída toda a série de fatores relevantes na análise final, nem, de fato, toda a série de análises relevantes para a compreensão do material que já ocupa suas notas e textos”. (p. 359)

Inspirados por trabalhos como Dantas (2008), Weber (2010) e Strathern (2014), seguimos com uma metodologia que tenta observar o material coletado (entrevistas, conversas, aulas, caderno de campo, workshops e outros documentos, o registro de processos dos experimentos artísticos), procurando constituir assim um primeiro nível de análise. Afinal, consideramos, conforme Strathern (2014, p. 349-50), que estamos diante de um quebra-cabeças oferecido pelo trabalho de campo num período isolado de tempo. Com esse procedimento se identificam palavras ou frases que entendemos constituir unidades de significado, também conhecidas como "menor informação autossuficiente". (Guba \& Lincoln apud Lapérrière, 1997) Em seguida, pudemos integrar as unidades de análise às cenas descritivas, transformando-as em categorias de análises (conjuntos de sentidos mais amplos).

Para a análise, as informações foram revistas à luz de autores como Gonçalo M. Tavares, José Gil, Gaston Bachelard, Erin Manning, William Forsythe e André Lepecki, que possibilitaram uma transição possível para a relação entre a dança e conhecimento. Assim, buscamos realizar um constante trânsito entre as questões da pesquisa, sempre tencionando fazer novas perguntas sobre desenvolvimentos posteriores. (Strathern, 2014)

\section{Um pequeno histórico}

No contexto de Berlim, os treinamentos para profissionais envolvem práticas corporais que não se constituem necessariamente como técnicas. No dicionário Houaiss, "prática" denota, entre outros sentidos, o ato ou efeito de praticar, fazer algo, executar alguma atividade rotineira - ação, realização, exercício. O treinamento estaria ligado então à prática de um conjunto de exercícios, do aquecimento às sequências de movimento, formas de se iniciar processos de pensamento e estratégias de trabalho. Práticas que por sua vez são dinâmicas e abertas, centrais para se sustentar o próprio indivíduo e o trabalho criativo. Envolvem ainda uma contínua e complexa negociação intelectual e psicofisiológica, paradigmas e discursos sobre técnicas, preparação corporal, saber incorporado (embodied knowledge), corporeida- 
de, pensamento coreográfico e improvisação. Os conceitos-chave de Pierre Bourdieu para prática e habitus serviram também como aporte para as análises empíricas desta pesquisa e para pensarmos a questão do treinamento ${ }^{3}$.

Por ocupar um lugar diferenciado da ideia de práticas corporais e por relacionar-se com a noção de treinamento, o conceito de técnica merece um pouco de atenção. Marcel Mauss (2003) conceitua técnica como técnicas do corpo, reconhecendo sua pluralidade e a identificando como algo imposto ao indivíduo pela sociedade. Mauss observa que as técnicas estão ligadas ao treinamento, ao aprendizado e ao hábito. O que parece importante deter em sua definição é a noção de corpo como "o primeiro e o mais natural objeto técnico, e ao mesmo tempo meio técnico, [...] antes das técnicas de instrumentos, há o conjunto das técnicas do corpo". (p. 407) A partir do trabalho de Marcel Mauss, Márcia Strazzacappa (2012, p. 28) é quem nos lembra que as técnicas corporais não são somente adquiridas, mas também "esquecidas", pois no momento em que se domina um movimento técnico já não seria mais preciso pensar para executá-lo, dado que ele já se encontraria integrado ao corpo, como se assim se fechasse um ciclo de aprendizagem.

Essa compreensão se liga também à ideia dos automatismos corporais, ou seja, aos hábitos, o que Eugênio Barba chamou de "conhecimento tácito” (Strazzacappa 2012, p. 28), processo também chamado de embodiment

\footnotetext{
3 Bryan S. Turner confere relevo à relação intrínseca entre as noções de embodiment e de habitus e, assim, citando Bourdieu, faz lembrar que "a maneira como as pessoas tratam seus corpos revelam as disposições mais profundas dos habitus". (Bourdieu, 1984, p.190 apud Turner, 2012, p. 70) O habitus integra assim um princípio corpóreo, essencialmente físico, e estaria incorporado pelos atores em seus processos de socialização, ou seja, em suas inserções sociais. No que tange a esta pesquisa, isso aponta para os contextos de inserção no campo da dança contemporânea.
}

(conhecimento encarnado). Barba (2004, p. 72), porém, ao analisar sua habilidade de se apegar ao erro em vez de imediatamente corrigi-lo, descreve esse processo como algo "enterrado em seus nervos e no músculo de seu coração".

Além disso, cumpre lembrar que as formas de conhecimento implicadas nas praticas corporais da dança contemporânea se relacionam com formas de conhecimento que são explicitas e implícitas. (Polanyi, 1966) De modo geral, sua forma explícita diz respeito às disciplinas do corpo e também ao conhecimento produzido por meio da linguagem discursiva, capaz de formar conceitos - ligadas por exemplo a situações mediadas pela fala, como as aulas e os workshops. Ao passo que o conhecimento implícito ou tácito estaria mais ligado ao conhecimento encarnado, a um processo corporal que se dá como algo "enterrado em nervos e músculos do coração", como exprime Barba ao analisar sua habilidade de "se apegar ao erro em vez de imediatamente corrigi-lo". (2004, p. 72)

Bales e Nettl-Fiol (2008, p. X) consideram que o trabalho do bailarino se tornou mais voltado para si mesmo em vez de fazer com que ele se esforce para espelhar aqueles que trabaIham. De modo que os bailarinos se tornaram seus próprios guias e passam a organizar seus treinos de acordo com suas próprias necessidades e interesses. Com efeito, no campo do treino da dança contemporânea norte-americana, desde o período histórico conhecido como a "era Judson"4 (Bales, 2008), a compreensão da técnica na dança se distinguiu das abordagens anteriores por várias maneiras: "Uma for-

\footnotetext{
4 Para estas autoras, Bales \& Nettl-Fiol (2008) o período Judson produziu uma mudança no paradigma com relação a dança, movimento, coreografia e ao treinamento. Nesse mesmo sentido, ver também Banes (1987).
} 
ma tem a ver com a aparente disjunção entre técnica, treinamento e performance ou coreografia". (Bales, 2008, p.1. Tradução nossa) As práticas voltadas para o treinamento da dança, segundo Bales, são distintas das cultivadas no período anterior, sendo marcadas daí em diante por uma abordagem eclética. A saber, pela incorporação do campo somático e de outras práticas físicas assimiladas pela técnica de dança na própria técnica. Poderíamos citar ainda, de acordo com Bales, a inclusão do balé como complemento a outras formas mais contemporâneas e as mudanças nas fronteiras entre o dançarino e o coreógrafo. (Bales, 2008) Como decorrência desse processo, temos que:

A choreographic preference for nondancerly took artists from the 1960 to somatic practice as a method for identifying movement principles and eroding dancerly habits in much the same way earlier dance educators like Margaret H'Doubler searched for "natural" or normative movement. (...) The boundary between training and performance/choreography is both blurred and overlapping in post-Judson training. (Bales, 2008, p. 2)

Assim, a visão do treino que envolvia técnica se expandiu, iniciando um rompimento e dando surgimento a outras formas de exploração da arte da dança, bem como a uma "posição crítica" com relação à técnica ela mesma. Bales trabalha com diferentes coreógrafos e bailarinos situados no circuito norte-americano cuja ênfase estaria nas suas palavras, "se transformarem artesanalmente no material artístico". (Bales, 2008, p. 10. Tradução nossa) Algo desse cenário histórico da dança ainda pode ser observado no contexto dos treinos de Berlim e no próprio trabalho de Hamilton. Bales considera, contudo, que o treinamento estaria situado entre as questões que afetam a coreografia, a história e a crítica. Ao examinar alguns aspectos do treinamento dos coreógrafos e bailarinos com quem trabalha, ela observa que o treino "tornou-se meio através do qual as idéias de movimento nascem, transmitem-se e se transformam". (Bales, 2008, p. 10. Tradução nossa)

Noutras palavras, depois do advento da dança moderna, as práticas de criar dança começam a se distanciar de um regime de treinamento técnico especifico. (Foster, 2011) No começo do treino da dança moderna, os bailarinos procuravam incorporar técnicas, estilos e ideais de seus coreógrafos. (Bales, 2008) Recentemente, contudo, os bailarinos começaram a treinar diferentes formas e gêneros, ocorrendo assim, de certa forma, uma separação entre a dança e o treino. (Foster, 2011, p.176) O treino se torna, desse modo, algo versátil, pois a criação coreográfica começa a exigir corpos mais disponíveis e detentores de outros habitus, de diferentes habilidades e de uma variedade de identidades culturais e individuais. Nesse sentido, o bailarino passa a buscar outros treinamentos, como o circo, a ginástica, práticas orientais, etc. e uma variedades de práticas que podem ser reunidas sob o conceito guarda-chuva da Educação Somática.

A ideia de o treino se tornar mais versátil acabou fazendo, por sua vez, com que, sob um novo paradigma, alguns autores passassem a considerar o corpo do bailarino como um corpo híbrido (Louppe, 2000), eclético (Davida, 1993), ou, segundo Elizabeth Dempster (2011), como um corpo pós-moderno, que estaria em processo de se destreinar de seus padrões de movimento.

Dentre todas essas possibilidades, o trei- 
namento no contexto do profitraining, do qual Hamilton faz parte, parece avançar principalmente para a ideia de laboratório e working progress. Nela, o estúdio se configura assim como condutor para a dança, para ideias de movimento, e como lugar destinado ao preparo do corpo para a performance. (Bales, 2008, p. 3) No caso específico de Hamilton, acontece um embaralhar-se das fronteiras entre o treino e o trabalho de cena. Ao longo das aulas e workshops, é esse o caminho percorrido para que passemos dos exercícios de improvisação à composição em nível mais acabado. Há, portanto, momentos coreográficos e performáticos que acontecem e que poderiam perfeitamente pertencer a uma performance pública. O habitus do bailarino não se formata segundo o modelo do coreógrafo. A bem dizer, na composição instantânea proposta por Hamilton, não há um modelo. Durante o processo parece haver espaço para a integração de diferentes experiências do bailarino e para a construção de sua corporeidade, que se desdobra em devires nos quais se transforma o movimento comum e se "convoca os poderes de metamorfose do corpo". (Gil, 2005, p. 197)

De muro a guerreiro:

o trabalho com a imaginação na composição instantânea de Julyen Hamilton

Quem é você em nós em você neles? Quem é você, quando está em trânsito por aquilo que nós somos? Quem é você junto a outras pessoas que estão dançando ou junto a pessoas que têm a mesma imaginação que você? Quem é você na beirada que cruza o centro, que perde tudo, que ganha, que apenas passa? Quem sou eu, agora que você está ao meu lado? (Hamilton, 2015)
As perguntas acima foram proferidas por Hamilton durante a primeira parte do treinamento "Trabalhando com Objetos", em um momento do aquecimento em que todos estão no espaço, concentrados na exploração, na improvisação e no compor espontâneo de pequenas cenas. Durante esse primeiro momento, perguntas como essas foram lançadas não necessariamente para serem respondidas, mas para pensarmos enquanto estamos em movimento. Pois, para Hamilton, se dançamos com outras pessoas há uma questão que se propõe: "quem somos nós na configuração ou na situação que se forma?" O mais importante seria, assim, "manter-se atualizado no fazer" (Hamilton, 2015) e não necessariamente tirar uma conclusão ou se congelar em uma ideia, personagem ou situação. A consideração de se manter atualizado agencia, contudo, vários conceitos, como o da presença, o da relação consciência e corpo, o da imaginação, entre outros, que serão explorados a seguir.

Durante um segundo momento do treinamento, Hamilton começou a nos abordar individualmente, interrompendo-nos em meio ao movimento com apenas uma pergunta: "o que você é?" A partir dessa prática, ele notou que a primeira resposta era sempre algo muito banal. Por exemplo: "eu sou um muro", "eu sou uma mulher com uma camisa verde". Mas logo em seguida, ao insistir e perguntar novamente, algo diferente vinha à tona: "eu sou um guerreiro!". De muro a guerreiro se revelou um trabaIho de corpo, isto é, um trabalho de movimento e pensamento, mas também de imaginação, o que pareceu se caracterizar como um processo concêntrico rumo ao excêntrico. Algo que se cristaliza e explode; portanto, que se abre. Conforme indica José Gil (2004, p. 12), abrir o corpo "é abrir o espaço de agenciamento de 
fluxos de intensidades". É um ponto de partida para pensar processos artísticos em devir.

Sobre o potencial do movimento na improvisação ou na criação, William Forsythe (2003, p. 1, apud Manning, 2009, p. 21. Tradução nossa) considera que deveríamos "ser capazes de dizer a qualquer momento: qual é o potencial dessa configuração do meu corpo?", o que Erin Manning (2009, p. 21) sintetiza como a potencial habilidade do movimento de se ampliar em "muitos de um". Assim, para a estudiosa, esse potencial de configuração estaria também ligado ao seu fator evanescente, gerando sempre o devir. Em conjunção com esse fator evanescente, Manning associa ainda o conceito de concrescência (concrescence) de Albert North Whitehead, traduzido por ela de modo literal como "crescendo junto" (growing together). Dessa forma, o conceito de concrescência propiciaria um "estar junto" (togetherness) e a produção de novidade.

Para ela, o potencial de configuração de que fala Forsythe envolverá sempre a produção da novidade, baseando-se nesse "estar junto" e em um processo de ampliação e de expulsão, ou seja, em algo que cresce. Na composição instantânea "estamos juntos", jogando com os devires, produzindo situações novas, mas também interagindo com a diferença na repetição ${ }^{5}$ (Deleuze). São processos que parecem também se configurar em ampliações e expulsões - como a transformação, ou a "produção de novidade", ou a passagem do "ser muro a ser guerreiro", ou os movimentos que geram

5 "The body moves. Repetition is the recomposing of the moving-with that is the relacional body. This movement-with can be a spiral of preacceleration that incites a displacement, or it can be a movement of thought. When this difference takes form, it becomes an actuality, an event in and of itself. This becoming-event creates a memory that feeds into future movement. Movement is repeating the future: dancing the not-yet." (Manning, 2009, p. 25). "muitos de um" ou "um de muitos". Estamos próximos, assim, dos fluxos de intensidade de que fala Gil, ou dos processos de interpenetração entre o individual e o coletivo (como traduziu Hamilton na expressão sintética: "quem é você em nós em você neles?"). Bem como dos processos entre movimento e pensamento: "quem é você na beirada que cruza o centro, que perde tudo? (...)". Ou, conforme Manning (2009, p. 22), viriam a primeiro plano as relações entre o coletivo e o individual e entre $o$ pensamento e o movimento:

Localizar os muitos em um e acrescentar um é sugerir que cada momento é primeiro, e acima de tudo, coletivo: coletivo e singular. É coletivo no sentido de que é relacional, que tem um efeito profundo na composição de suas intensas extensões. Essas intensidades se transformam em movimentos de pensamento, onde o pensamento nunca é distinto do movimento em si".

Sobre o conceito de imaginação também é possível observar, segundo aponta Gonçalo M. Tavares (2013a, p. 369), que "a imaginação é uma questão que joga sempre com o dentro e o fora. Aliás, o próprio espaço onde se desenvolve a imaginação é um espaço interior, não visível". De outra forma, Tavares (2013a, p. 368-9) analisa a imaginação como uma "imprevisibilidade de saltos temporais" (como é possível perceber, houve o salto de muro a guerreiro, completamente imprevisível). No que diz respeito à relação da imaginação com os objetos, e para pensarmos o exemplo da transformação do intérprete "de muro a guerreiro", observamos que Gaston Bachelard (1990, p. 16, citado por Tavares, 2013a, p. 383) considera a imaginação um instrumento que age sobre as coisas, alterando-as como uma droga, mudando a dimensão dos objetos. 
Nesse sentido, Tavares chama atenção para o "potencial imaginativo que cada objeto ativa em cada observador". O objeto ganharia assim um "potencial de ativação do imaginário". (Tavares, 2013a, p. 384) Um potencial que se constitui como "um motor do início de algo", processo no qual, a partir de uma aparente imobilidade, o intérprete, interiorizando-se como muro, ou se relacionando com qualquer objeto, daria lugar a alguma coisa que "vem à tona", de modo que o observador parece "fazer algo com o que viu (interiormente, para já). No fundo seria uma questão de ver para fazer e assim poder entrar numa outra fase, a fase pública (...)". (Tavares, 2013a, p. 384)

Ou então, numa formulação mais completa, seria esse o momento em que estamos...

... na fase em que saindo para o exterior as ideias excitadas procuram matérias concretas onde possam se exprimir. Da contemplação de um grão de poeira (ou de uma ervilha ${ }^{6}$ ) poderá sair a intenção irredutível de construir um palácio. E se tal sucede é porque estamos perante a resposta humana ao potencial de activação do imaginário de uma substância, neste caso, o grão de poeira; e essa resposta briIhante chama-se fazer (Tavares, 2013a, p. 384) (Os grifos são do autor).

Entre o "potencial de ativação do imaginário" e o "fazer" que o objeto pode propor, parece se interpor o conceito de affordance ${ }^{7}$

6 A referência à ervilha é trazida por Tavares (2013a, p. 383), a partir de uma história de Roland Barthes, segundo a qual os monges budistas eram capazes de ver uma grande paisagem em uma ervilha.

7 Segundo as concepções de Alva Noë (2004, p.106), do ponto de vista enativo, todos os objetos da percepção seriam affordances, de modo que, poder experienciar seus atributos, seria "agarrar seus contornos sensório-motores", experimentando os objetos como "determinadas possibilidades de e para o movimento". Ao passo que para Tavares (comunicação pessoal, 2013b), a questão que se propõe é: "como olhar para as coisas?". Os objetos seriam catalizadores do pensamento, possibilitando o pensamento. Conceito que parece ser po- do psicólogo James J. Gibson (1977; 1979). Assim, de muro a guerreiro, não se sabe muito bem onde o devir pode nos levar, mas pela dança, pelo fazer e pelo affordance chegamos a momentos de especificidades. Para Hamilton (2015) a imaginação é algo fisiológico ou emocional, não somente racional, pois haveria algo dentro de nós que "toca" a imaginação e a alimenta. O movimento, contudo, seria uma forma de produzir a imaginação. Segundo o coreógrafo, seria possível vermos a imaginação conforme realizamos nossos passos. Essa seria uma forma de não nos movermos de modo mecânico: "quando você faz seu exercício, você faz de dois jeitos; ao se voltar para baixo, ao tocar o chão, você pode usar a sua imaginação e se deixar alimentar por ela. Esse tempo e modo particular de se levantar alimenta a imaginação". (Hamilton, 2015) Para Hamilton, portanto, haveria duas direções para a imaginação - de onde provém o movimento, alimentado pelo fisiológico, o emocional ou até mesmo o racional e a própria imaginação, que é alimentada pelo movimento.

Ao aprofundar o conceito, Gonçalo M. Tavares (2013a, p. 377) recupera de "O Ar e os Sonhos", de Bachelard, a ideia de que a imaginação é a faculdade de "deformar" as imagens fornecidas pela percepção e, portanto, de "eliminar o primeiro pensamento". Nas palavras de Gonçalo M. Tavares, a ideia seria "fugir do primeiro encontro entre pensamento e percepção", de "fugir do sítio esperado". Algo que também foi mencionado por Hamilton em várias situações durante seu treinamento. Para Hamilton, contudo, isso implica não apenas nos atermos à primeira ideia, mas também à segunda ou à terceira e assim por diante. Pois

tente também para o trabalho com a composição instantânea de Hamilton. 
a prática é saber que "há outras centenas de vida" (Hamilton, 2015) que se pode ter nesse encontro entre o pensamento e a percepção. É poder também notar o processo em tempo real de modo físico e não intelectual.

Segundo Hamilton, com a composição instantânea, uma maneira de se trabalhar a imaginação seria partir de algo concreto, um conhecimento real, um objeto literalmente. O próprio tangível seria uma forma de ativar a imaginação. Julyen Hamilton considera portanto que a concretude do objeto pode produzir algo em nossa imaginação, pois "o básico da imaginação é a realidade". "Começa-se por imaginar a realidade, treinamos imaginando a realidade". (Hamilton, 2015) Assim, para chegarmos à realidade, tocamos o chão e podemos experienciar a "realidade em nossa imaginação". (Hamilton, 2015) Ou seja, trata-se do momento preciso em que sei da temperatura, da textura do chão, de uma de suas qualidades. Quando o que temos em nossa percepção e em nosso pensamento (objeto, chão, outro intérprete) torna-se claro, a transformação poderá acontecer, e com ela o acesso à imaginação.

Haveria assim em sua concepção para a composição instantânea - que muitas vezes ele chama de técnica - uma via de mão dupla entre imaginação e realidade. "Realidade e fantasia vivem juntos sem ser uma contradição". "Como sentir as articulações na atualidade do corpo (no corpo presente e não na fotografia) e poder imaginá-las? Essa é a técnica". (Hamilton, 2015)

Tavares (2013a, p. 394) considera que a imaginação vive de oposições, de duelos entre o sim e o não, visto que a imaginação estaria sempre diante de "infinitas possibilidades" em meio às quais a "mente racional", ao eleger entre oposições, escolheria entre duas coisas, empurrando-se ao final para uma decisão, para a escolha de uma só. Tavares (2013a, p. 395) utiliza a imagem do duelo, que é: "precisamente a impossibilidade de adiar, de suspender: mato ou morro; tenho pois de agir. (...) Só assim a imaginação pode passar para o exterior, pois no exterior não há tempos duplos: podemos fazer uma coisa e depois o seu oposto, mas não podemos ao mesmo tempo fazer uma coisa e o seu oposto".

Hamilton, contudo, inversamente, nos alerta de que podemos pensar ao mesmo tempo em duas direções, mas não podemos fazer duas coisas ao mesmo tempo, como, por exemplo, nos mover rápido entre a direita e a esquerda. Nesse sentido, o lugar do pensamento é o da imaginação e o do funcionamento da "mente racional", isto é, o da consciência clara e intencional de que fala José Gil $(2004,2005)$ e o de sua relação com o inconsciente. O corpo impregnado de consciência se caracteriza por sua hiperexcitabilidade, e por captar as pequenas percepções dos outros corpos. Seu problema é que ele se encontra "enterrado pelas funções macrosensoriais do corpo empírico". (Gil, 2004, p. 5) Ele é no entanto capaz de se transformar por um processo de "contato-osmose com os outros corpos", de forma que a relação que se trava nesse processo se dá entre o consciente e o inconsciente. Para Hamilton, contudo, na composição instantânea é necessária a rapidez e a decisão, mas a decisão como corte, como "des-cisão".

Sobre a rapidez, ouvimos de Hamilton (2015) a sugestão de que fôssemos "rápidos nos olhos. Rápidos para fazer alguma coisa, rápidos para que algo aconteça. Rápidos para notar um ângulo, rápidos para sentir temperatura". De modo que o bailarino, consciente ou não desse funcionamento da consciência cla- 
ra e intencional, sabe que a rapidez seria uma forma de não falharmos com o movimento, caindo em preocupações ou em conclusões. Como diria Steve Paxton (citado por Gil, 2005, p. 108), seria necessário buscar a forma "mais consciente inconsciente possível" de se mover entre o espontâneo e o controle. Para Tavares (2013a, p. 376), nesse sentido, a decisão na imaginação se liga a um instinto de velocidade, pois o "imaginador", em contraposição com o pensador, traz algo de imediato. Ele "decide" entre as inúmeras possibilidades, ao passo que o pensador, para Bachelard, hesita e percorre um "longo caminho de reflexão". (Bachelard, 1996 p.167, citado por Tavares, 2013a, p. 376)

Barba (1995) ao refletir sobre os exercícios para atores considera, de um modo geral, que: "um bom exercício é um paradigma de dramaturgia, isto é, um modelo para o ator." (Barba, 1995, p. 100. Tradução nossa) Portanto, para Barba, os próprios exercícios são definidos como paradigma da dramaturgia. São forma pura, a evolução dinâmica, mas ainda desprovida de enredo ou história. Nesse sentido, os exercícios se configuram como pequenos labirintos nos quais: "os corpos-mentes do ator podem rastrear e retraçar, a fim de incorporar um modo de pensar paradoxal, distanciando-se, assim, de seu próprio comportamento cotidiano e entrando no domínio do comportamento extra-cotidiano do palco"8. (Barba, 1995, p. 100. Tradução nossa) Dessa forma, o modo como Hamilton concebe seus exercícios se aproximaria desse paradigma dramatúrgico de que fala Barba. Para ambos, os exercícios fazem $\circ$ ator ou o bailarino se distanciarem desse corpo trivial, como diria José Gil (2005).

8 No original: the actor's body-minds can trace and retrace in order to incorporate a paradoxical way of thinking, thereby distancing themselves from their own daily behavior and entering the domain of the stage's extra-daily behaviour.
Ou, nas palavras de Barba, eles propiciariam a passagem do modo cotidiano para o extracotidiano.

É interessante notar, nas análises de Barba, a importância dada ao pensamento em conexão com as práticas, ambos funcionando como materiais para uma art form. E, de fato, como é poético o dizer de Barba sobre a idade dos exercícios, sendo o mais velho a "biomecânica" de Meyerhold. Poético é também seu relato sobre o começo do século $X X$ quando Stanislavski, Meyerhold e seus colaboradores inventaram "exercícios" (as aspas são colocadas por Eugênio Barba) para a formação dos atores. Ali dava-se à luz um paradoxo. Pois, enquanto as escolas de teatro praticavam balé, canto, esgrima etc. - seguindo uma tradição e portanto tendo em vista sempre a encenação de fragmentos de peças clássicas - esse grupo de autores criava "exercícios" como fins em si mesmos. Por exemplo, a criação de detalhadas partituras (scores) codificadas até o menor detalhe.

Com a mesma verve, Barba (1995, p. 101) descreve dez elementos em torno disso que, em sua opinião, caracterizaria o trabalho com exercícios e sua relação eficaz com a dramaturgia. É curioso notar como essas características ainda ecoam nas práticas do treinamento da dança, inclusive em Hamilton. Nele, ainda divisamos ideias fundamentais como: o pensar com o corpo e com a mente; o trabalho com movimentos extra-cotidianos; a repetição que não torna o exercício chato e permite descobrir novos detalhes, novas formas de se começar a partir de algo familiar; a presença que permite cativar o público.

Tanto Barba quanto Hamilton chamam atenção para o processo de se pensar a continuidade e a dinâmica pelas quais os exercícios 
são constituídos, isto é, suas fases e segmentos envolvendo ações perceptíveis. Assim, o exercício seria uma espécie de diagrama. $O$ que o tornaria diferente não seria o exercício em si e o fato de possuir sempre os mesmos traços, mas a possibilidade de variá-los em sua "espessura, intensidade e dinâmica". (Barba,1995, p. 101)

É assim que o treinamento para Hamilton estaria para além da tarefa de sustentar o trabalho do artista ou de apenas servir como uma via para manter o corpo em forma. Seus exercícios chegam a ser sua própria performance, por isso se tornam um locus de invenção e descoberta. Como em Barba, são como pequenos labirintos que o artista pode percorrer e deles incorporar pensamentos e corpos paradoxais. São também como amuletos que, embora ocultos, encontram-se sempre à mão para que deles se possa retirar certas "qualidades de energia". São, por fim, feitos de memória, corpo-memória. Um exercício se torna memória que atua por todo o corpo. ${ }^{9}$ (Barba, 1995, p. 100)

\section{Conclusão}

Hamilton considera que o básico da imaginação é a realidade, já que a realidade toca a imaginação. Treinamos assim a capacidade de imaginar a realidade, pois a composição instantânea demanda imaginação. Mas a realidade nos leva, por outro lado, ao mesmo tempo à imaginação, quando por exemplo tocamos o chão. A realidade desse chão pode nos levar para outros lugares que não o abstrato, para uma "zona em que o corpo, visto do exterior

9 No original: made up of memory, body-memory. An exercise becomes memory, which acts through the entire body. do interior, entra em contágio com o mundo". (Gil, 2004, p. 11) Como diria ainda Gil (2005; 2004), trata-se da "zona do devir constante". Para Hamilton (2015), esses lugares podem se desdobrar em emoções, políticas, sentimentos, histórias. O movimento alimenta a imaginação, pois ao nos movermos, "sentimos algo" que muitas vezes não podemos colocar em palavras, "mas como sentimos, podemos convocar o mundo da fantasia". (Hamilton, 2015)

Por esse caminho, também podemos sentir o começo do próximo movimento. Para Barba (1995, p. 101), é importante que se cultive o pensamento sobre a continuidade dos exercícios. Mesmo que a passagem entre dois pontos não seja linear, a precisão envolve sempre um começo, um meio e um fim. Erin Manning (2009, p. 34) fala da sensação de elasticidade quando o movimento começa a se dobrar em um outro movimento, abrindo-se para formas e deformações. Essa "dobra ao infinito" manifesta uma sensação "múltipla, mas não multiplicada". (Manning, 2009, p. 34) Assim, agenciamos sentidos, habilidades corporais, o se dobrar dos movimentos conforme dançamos ou compomos de modo instantâneo, podendo imaginar sempre outros movimentos com precisão, podendo "da imaginação chegar ao corpo" (Hamilton, 2015) e do que é tangível chegar à imaginação.

A relação entre a consciência do corpo e a imaginação, para Hamilton (2015), é uma relação perigosa, pois a consciência do corpo desafia a imaginação, instilando a dúvida e a hesitação de que falavam Bachelard e Tavares. Para Hamilton (2015), contudo, a imaginação abre espaço no corpo se constituindo como "o começo profundo da autonomia". Ele considera ainda que o corpo é conectado com o "sólido do mundo", tornando a materialidade 
da dança um privilégio para sua forma de arte.

No que toca à questão dos treinamentos na dança, seria interessante inventariar e discutir a riqueza das práticas corporais contemporâneas, exemplo das quais se afigura o trabalho com a imaginação em Hamilton. Em determinados contextos, como o de Berlim, esse trabalho seria uma maneira de dar voz ao imenso pensamento que é produzido por coreógrafos que muitas vezes advém de situações com os alunos, do contexto de aulas e da própria dança.

O que esses autores da dança contemporânea estão fazendo e por quê? O que sua atividade revela sobre a dança e sobre si próprios como artistas? De que forma dialogam com os aspectos da era Judson e da era pós-Judson, isto é, como as práticas do passado coexistem com as práticas do presente? $\mathrm{E}$, por conseguinte, que história da dança é assim contada ou referenciada? No treinamento da dança, de que modo o corpo dialoga com os "padrões estéticos das celebridades" e obedece "a uma certa normatividade 'científica', relativa ao que a ciência diz que é bom para a saúde e as revistas nos transmitem como a perfeição em saúde ou em estética"? (Pelbart, 2015, s/n) E por fim, como fazer a crítica da Educação Somática, matéria já bastante imbricada no treinamento da dança?

Essas questões parecem ser mais pertinentes do que questões sobre a existência ou não do espelho em sala de aula, sobre a autoridade do professor, sobre o palco italiano, ou sobre se estamos diante de um corpo híbrido, eclético ou disciplinado. Concordamos com Pál Pelbart (2015, s/n) na afirmação de que não estamos mais diante "do corpo do hostilizado e disciplinado". Estamos, nas palavras do filósofo, diante da hiperprodução, da conexão e da produtividade, da imagem e dos estímulos incessantes que por vezes nos limitam a não pensar e a simplesmente reagir.

Com relação ao campo Somático, talvez estejamos diante do engaiolar de alunos e artistas na falta da técnica. Por mais que consideremos a possibilidade de melhorias na técnica e na poética que o campo Somático engendrou, ele pode, na realidade, limitar o artista e suprimir o campo da dança como um campo autônomo. De modo que, no contexto da dança contemporânea como forma de arte, a relação com a saúde ou com o modo de se cuidar do corpo propostos pela Educação Somática são decisões pessoais, éticas, que não deveriam ser tratadas como um imperativo teórico, como muitas vezes a Educação Somática parece se impor.

O que pudemos perceber até agora com relação ao treinamento de práticas estudadas durante o doutoramento é que elas vão além da história da dança, remetendo contudo à história da arte. No caso de Julyen Hamilton, por exemplo, parte do seu pensamento e referências dialogam com a Literatura, com Shakespeare e Blake. A prática da Educação Somática se encontra dissolvida em sua arte, e não se reduz ao Somático.

Dentre os muitos elementos trabalhados no treinamento de Hamilton, bem como no contexto do treinamento para profissionais em Berlim, a questão do treino se aproxima da ideia apresentada por Renato Ferracini ${ }^{10}$ (2015) ao buscar a etimologia da palavra treinamento. Além do sentido de norma e de normatização, Ferracini encontrou no Latim a palavra

$10 \mathrm{Em}$ palestra no Seminário Permanente em Performance e Filosofia, realizado no contexto do AELab - Laboratório de Estética e de Filosofia das Práticas Artísticas do IFILNOVA Instituto de Filosofia da Universidade Nova de Lisboa, em 04 de dez. 2015. 
tradinare, que significaria "ensinar o falcão a caçar". Seria o caso portanto, em última análise, de intensificar uma qualidade já existente (para o falcão, a de caçar, algo que já lhe pertence). No trabalho de Ferracini o treinamento serve, entre outras funções, para intensificar a percepção e o fazer de um ator já imerso em um fluxo de experiência. Em Hamilton, o treinamento de vários elementos, como a imaginação, a escuta, a percepção, a presença e o espaço, serve para que o bailarino se atualize o tempo todo e intensifique cada uma dessas capacidades no devir coreográfico, onde os exercícios podem sair da potência para produzir possibilidades em prol da arte.

O treinamento também estaria ligado a uma ideia de laboratório, o que complementa o propósito de ser, mais que um lugar de construção de habilidades, o da invenção e da descoberta. $\mathrm{Na}$ área científica, a natureza do laboratório é produzir o futuro, mas também ficar aquém do absoluto contemporâneo, na medida em que existem pesquisas em andamento ou coisas que ainda não foram descobertas. O treinamento da dança, concebido como um laboratório, implica se situar nessa fratura. Convém notar assim que, no laboratório da dança, retêm-se muitos dos achados pesquisados, pois nem tudo se transforma em produto. Parece haver nele também uma não linearidade, em contraste com o esquema criado pela sociedade em que primeiro se aprende e depois é que se trabalha. $O$ que quer dizer que, nesses contextos de treinamento como laboratório, o processo de aprendizado não acontece necessariamente antes do processo profissional, fronteiras que se encontram borradas. De modo que um estudante ou principiante da dança pode frequentar um treinamento como o do contexto berlinense, junto com um profis- sional da dança, promovendo ainda um intercruzamento geracional e cosmopolita.

De certa maneira, um treinamento como de Hamilton iguala profissionais e não profissionais da dança, pois todos são convidados a um mergulho vertiginoso em propostas como o trabalho com a imaginação. A finalidade é a composição instantânea, a transformação do corpo trivial no corpo dançado ou extracotidiano e, no que tange à pedagogia de Hamilton, a promoção da autonomia do bailarino. Por fim, a dança parece ser central para se re-pensar qual o papel e as forças do corpo em movimento, numa "re-imaginação" do que pode o corpo, do que a dança pode ser e do que o corpo pode ser. (Lepecki, 2014)

\section{Referências}

BALES, M.; NETTL-FIOL, R. The body eclectic: evolving practices in dance training. Illinois: University of Illinois Press, 2008.

BANES, S. Terpsichore in Sneakers: Post-Modern Dance Theater. Middletown: Wesleyan University Press, 1987.

BARBA, E. Children of Silence: Reflexion on forty years of Odin Teatre: To the secret people the friends of Odin. Trans. Judy Barba. Peripeti, Aarhus, Department of Dramaturgy/ University of Aarhus, n. 2, p. 65-74, October, 2004.

BARBA. E. An Amulet Made of Memory: The significance of exercises in the actor's dramaturgy. In: ZARRILLI, P. B. (Ed.). Acting (re) considered: a theoretical and practical guide. Routledge, 2005. p. 99-105. 
DANTAS, M. Ce dont sont faits les corps anthropophuges: la participation des danseurs dans la mise en œuvre chorégraphique comme construction des corps dansants chez deux chorégraphes brésiliennes. 2008, 434 p. Tese (Doutorado). Montréal, Université du Québec à Montréal.

DAVIDA, D. Le corps éclectique. Dans A. Gélinas (Dir.), Les vendredis du corps: le corps en scène, vision plurielle. Montréal: Édition Cahiers de théâtre Jeu/Festival International de Nouvelle Danse, p. 20-35, 1993.

DEMPSTER, E. Women writing the body: Let's watch a little how she dances. In: CARTER, A.; O'SHEA, J. (Ed.). The Routledge dance studies reader. London/New York: Routledge, 2010. p. 229-235.

FORTIN, S. Contribuições possíveis da etnografia e da auto-etnografia para a pesquisa na prática artística. Revista Cena, Porto Alegre, UFRGS, n. 7, p. 77-88, fevereiro 2009.

FOSTER, S, L. "Choreographing Empathy." iBooks. https://itunes.apple.com/WebObjects/MZStore. woa/wa/viewBook?id=11047B238E1BA6A06C489C79F17A83E9. 2011.

FOUCAULT, M. Vigiar e punir: nascimento da prisão. Trad. de Raquel Ramalhete. Petrópolis: Vozes, 1987.

GIBSON, J. The Theory of Affordances. In: Shaw, R. \& Bransford, J. (eds.) Perceiving, Acting, and Knowing. Hillsdale, NJ: Lawrence Erlbaum Associates, 1977.
GIL, J. Abrir o corpo. In: FONSECA, T. M. G., \& ENGELMAN, S. (orgs.). Corpo, arte e clínica. Porto Alegre: Editora da UFRGS, 2004.

GIL, J. Movimento Total: o corpo e a dança. São Paulo: Iluminuras, 2005.

HAMILTON, Julyen. Working with objects. Berlim, 11-16 de maio, 2015. Treinamento realizado no Radial System V. Informação Verbal.

HOUAISS, A.; VILLAR, M. S. Dicionário Houaiss da Língua Portuguesa. Rio de Janeiro: Objetiva, 2001.

LAPERRIÈRRE, A. La théorisation ancrée (grounded theory): démarche analytique et comparaison avec d'autres approaches apparentées. In: POUPART, J. et al. La recherche qualitative: enjeux épistémologiques et méthodologiques. Canadá: Gaëtan Morin Éditeur, pp. 309-340, 1997.

LEPECKI, A. O corpo colonizado. GESTO: Revista do Centro Coreográfico do Rio. Rio de Janeiro: RioArte, v. 3, n. 2. p. 7-11, jul. 2003.

LEPECKI, A. Performance and Corporeality, 2014. Lecture In: http://artmuseum.pl/en/doc/ video-performans-i-cielesnosc. Acesso em 13 de fevereiro de 2015.

LOUPPE, L. Corpos Híbridos. In: Lições de Dança, 2. Rio de Janeiro: UniverCidade, 2000.

MANNING, E. Relationscapes: Movement, Art, Philosophy. Massumi, B \& Manning, E. (eds.), MIT Press Cambridge, Massachussets, London/England, 2009. 
MAUSS, M. As técnicas do corpo. Sociologia e Antropologia. Trad. Paulo Neves. São Paulo: Cosac Naify, p. 401-420, 2003.

NOË, Alva. Action in perception. London: Massachusetts Institute of Tecnology, 2004.

PELBART, P. P. Entrevista com Peter Pál Pelbart. Disponível em: http://www.freudiana. com.br/textos-interessantes/entrevista-peter-pal-pelbart.html. Acesso em 18 de junho de 2015.

POLANYI, M. The Tacit Dimension. New York: Doubleday \& Co, 1966.

STRATHERN, M. O efeito etnográfico e outros ensaios. Trad. DULLEY, I., PINHEIRO, J, VALENTINI, L. São Paulo: Cosac \& Naify. 2014.

STRAZZACAPPA, M. Educação Somática e Artes Cênicas: princípios e aplicações. Editora Papiros, Campinas, 2012.

TAVARES, G. M. Atlas do corpo e da imaginação: teoria, fragmentos e imagens. Lisboa: Leya, 2013a.

TAVARES, G. M. Comunicação pessoal. Faculdade da Motricidade Humana, 2013b.

TURNER, B. S. Embodied Practice: Martin Heidegger, Pierre Bourdieu and Michel Foucault. In: Routledge Handbook of Body Studies. London/New York: Routledge. 2012. p. 62-74.
WEBER, S. Les pratiques du danseur-créateur vis-à-vis des pratiques dominantes en danse contemporaine: trois études de cas du doctorat en études et pratiques des arts. 2008, 341 p. Tese (Doutorado). Montréal, Université du Québec à Montréal.

Recebido: 31/08/2016 Aprovado: 19/12/2016 